Article

\title{
Update 2016-2018 of the Nationwide Danish Fungaemia Surveillance Study: Epidemiologic Changes in a 15-Year Perspective
}

\author{
Malene Risum ${ }^{1}$, Karen Astvad ${ }^{1}$, Helle Krogh Johansen ${ }^{2,3}$, Henrik Carl Schønheyder ${ }^{4,5}$, Flemming Rosenvinge ${ }^{6}$, \\ Jenny Dahl Knudsen ${ }^{2,7}$ (D), Rasmus Krøger Hare ${ }^{1}$ (D), Raluca Datcu ${ }^{1}$, Bent Løwe Røder ${ }^{8}$, \\ Valeria Stanislavovna Antsupova ${ }^{9}$, Lise Kristensen ${ }^{10}$, Jan Berg Gertsen ${ }^{10}$, Jens Kjølseth Møller ${ }^{11}$, \\ Esad Dzajic ${ }^{12}$, Turid Snekloth Søndergaard ${ }^{13}$ and Maiken Cavling Arendrup ${ }^{1,2,3, * \text { (D) }}$
}

check for updates

Citation: Risum, M.; Astvad, K.; Johansen, H.K.; Schønheyder, H.C.; Rosenvinge, F.; Knudsen, J.D.; Hare, R.K.; Datcu, R.; Røder, B.L.; Antsupova, V.S.; et al. Update 2016-2018 of the Nationwide Danish Fungaemia Surveillance Study: Epidemiologic Changes in a 15-Year Perspective. J. Fungi 2021, 7, 491. https://doi.org/10.3390/jof7060491

Academic Editor: David S. Perlin

Received: 25 May 2021

Accepted: 15 June 2021

Published: 19 June 2021

Publisher's Note: MDPI stays neutral with regard to jurisdictional claims in published maps and institutional affiliations.

Copyright: (C) 2021 by the authors. Licensee MDPI, Basel, Switzerland. This article is an open access article distributed under the terms and conditions of the Creative Commons Attribution (CC BY) license (https:// creativecommons.org/licenses/by/ $4.0 /)$.
1 Unit of Mycology, Statens Serum Institut, 2300 København, Denmark; mlri@ssi.dk (M.R.); kaas@ssi.dk (K.A.); rmj@ssi.dk (R.K.H.); Raluca.Datcu@rsyd.dk (R.D.)

2 Department of Clinical Microbiology, University Hospital of Copenhagen, Rigshospitalet, 2100 København, Denmark; hkj@biosustain.dtu.dk (H.K.J.); Inge.Jenny.Dahl.Knudsen@regionh.dk (J.D.K.)

3 Department of Clinical Medicine, University of Copenhagen, 1165 København, Denmark

4 Department of Clinical Microbiology, Aalborg University Hospital, 9100 Aalborg, Denmark; henschoenh@gmail.com

5 Department of Clinical Medicine, Aalborg University, 9220 Aalborg, Denmark

6 Department of Clinical Microbiology, Odense University Hospital, 5000 Odense, Denmark; Flemming.rosenvinge@rsyd.dk

7 Department of Clinical Microbiology, Hvidovre Hospital, 2650 Hvidovre, Denmark

8 Department of Clinical Microbiology, Slagelse Sygehus, 4200 Slagelse, Denmark; blro@regionsjaelland.dk

9 Department of Clinical Microbiology, Herlev and Gentofte Hospital, 2730 Herlev, Denmark; valeria.stanislavovna.antsupova@regionh.dk

10 Department of Clinical Microbiology, Aarhus University Hospital, 8200 Aarhus, Denmark; lise.kristensen@auh.rm.dk (L.K.); Jan.Berg.Gertsen@rm.dk (J.B.G.)

11 Department of Clinical Microbiology, Vejle Sygehus, University Hospital of Southern Denmark, 7100 Vejle, Denmark; Jens.Kjoelseth.Moeller@rsyd.dk

12 Department of Clinical Microbiology, Sydvestjysk Sygehus, 6700 Esbjerg, Denmark; Esad.Dzajic@rsyd.dk

13 Department of Clinical Microbiology, Sygehus Sønderjylland, 6400 Sønderborg, Denmark; Turid.Snekloth.Sondergaard@rsyd.dk

* Correspondence: maca@ssi.dk

Abstract: As part of a national surveillance programme initiated in 2004, fungal blood isolates from 2016-2018 underwent species identification and EUCAST susceptibility testing. The epidemiology was described and compared to data from previous years. In 2016-2018, 1454 unique isolates were included. The fungaemia rate was 8.13/100,000 inhabitants compared to 8.64, 9.03, and 8.38 in 20042007, 2008-2011, and 2012-2015, respectively. Half of the cases (52.8\%) involved patients 60-79 years old and the incidence was highest in males $\geq 70$ years old. Candida albicans accounted for $42.1 \%$ of all isolates and Candida glabrata for $32.1 \%$. C. albicans was more frequent in males $(p=0.03)$ and C. glabrata in females $(p=0.03)$. During the four periods, the proportion of $C$. albicans decreased $(p<0.001)$, and C. glabrata increased $(p<0.001)$. Consequently, fluconazole susceptibility gradually decreased from $68.5 \%$ to $59.0 \%(p<0.001)$. Acquired fluconazole resistance was found in $4.6 \%$ Candida isolates in 2016-2018. Acquired echinocandin resistance increased during the four periods $0.0 \%, 0.6 \%, 1.7 \%$ to $1.5 \%$ ( $p$ < 0001). Sixteen echinocandin-resistant isolates from 2016-2018 harboured well-known FKS resistance-mutations and one echinocandin-resistant $C$. albicans had an FKS mutation outside the hotspot (P1354P/S) of unknown importance. In C. glabrata specifically, echinocandin resistance was detected in 12/460 (2.6\%) in 2016-2018 whereas multidrug-class resistance was rare (1/460 isolates $(0.2 \%))$. Since the increase in incidence during 2004-2011, the incidence has stabilised. In contrast, the species distribution has changed gradually over the 15 years, with increased C. glabrata at the expense of $C$. albicans. The consequent decreased fluconazole susceptibility and the emergence of acquired echinocandin resistance complicates the management of fungaemia and calls for antifungal drug development. 
Keywords: Candida; candidaemia; candidiasis; resistance; echinocandin; mutation; epidemiology

\section{Introduction}

Candidaemia is the most common manifestation of fungaemia and of invasive candidiasis [1]. The overall 30-day mortality rate was $43 \%$ and even higher $(54 \%)$ in the intensive care unit (ICU) in a nationwide study in Denmark in 2010-2011 [2]. Host factors include multimorbidity and gastrointestinal disease [2]. Main risk factors are prior abdominal/complicated surgery, antibiotic exposure, an indwelling central venous catheter, and Candida colonisation [2]. The recommended first-line treatment of candidaemia is echinocandin [3-5].

The Danish candidaemia surveillance has existed since 2003 [6,7] and has been nationwide since 2004 [8-10]. The highest annual incidence in Denmark was 10.05/100,000 inhabitants in 2011 [9]. During the surveillance period echinocandin resistance has emerged and fluconazole non-susceptibility increased [10]. Echinocandin resistance has emerged particularly in C. glabrata. The target enzyme for the echinocandins, the $\beta$-(1,3)-D-glucan synthase, is encoded by the FKS genes [11,12]. Mutations in specific "hotspot" regions of FKS1 for all Candida species as well as FKS2 for C. glabrata lead to MIC elevation and reduce the sensitivity of the enzyme up to several thousandfold [13]. The position of the mutation, the specific amino acid alteration, and the species in which it is inserted all affect the level of resistance [11]. Therefore, FKS sequencing is highly informative and essential for interpretation, particularly of MICs close to the echinocandin breakpoint.

Denmark has the highest fungaemia incidence among the Nordic countries [14-18]. Suggested causes have been a higher antibacterial drug use and a higher prevalence of haematological malignancy [19]. The impact of antibiotic use was supported by a Danish study on ICU patients, which found that exposure to ciprofloxacin-containing antibiotics increased the risk of invasive Candida infections [20]. In contrast, the importance of differences in prevalence of underlying haematologic malignancy was not supported, as only a minority of Danish candidaemia patients had underlying haematological disease (9\%) [2].

Denmark has also experienced a larger shift in species proportion from Candida albicans to Candida glabrata than the other Nordic countries and has had the highest consumption of antifungal drugs in both the primary and hospital sector [19]. Prior antifungal use has been shown to lead to a higher proportion of candidaemia with non-C. albicans species, especially C. glabrata following azole and C. parapsilosis following echinocandin exposure [1] Azole antifungal agents are recommended as prophylaxis for certain patient groups in Denmark depending on their underlying disease and risk factors-especially in the ICU, in haematological patients, in low-birth-weight neonates, and in lung and liver transplant recipients [3].

Due to the changing epidemiology, the active nationwide surveillance programme has continued. Knowledge of the local epidemiology is important for timely revision of guidelines for initial antifungal therapy and informative with respect to whether changes in antifungal stewardship approaches, infection control, or prophylaxis strategies are needed. We report the most recent national data on the epidemiology of fungaemia including antifungal susceptibility over a 15 -year perspective.

\section{Materials and Methods}

\subsection{Isolates, Episode Definition, and Blood-Culture Systems}

Fungal blood isolates were referred to the National Reference Mycology Laboratory at Statens Serum Institut for species verification and susceptibility testing from the ten Danish clinical microbiological departments in the years 2016 to 2018. Thirteen isolates $(0.9 \%)$ were not referred for confirmatory identification and susceptibility testing, but are included in the analysis according to the species identification performed locally. These 
included: C. glabrata $n=6$, C. albicans $n=4$, C. krusei $n=1$, Candida parapsilosis $n=1$, and Candida dubliniensis $n=1$. Confirmatory species identification was performed based upon morphology and Matrix-assisted laser desorption/ionisation time-of-flight mass spectrometry (Bruker, Bremen, Germany) [9] with the online available spectrum database MSI [21] or DNA sequencing as previously described when needed [10].

Isolates were considered unique despite originating from the same patient if either (a) belonging to a different species, (b) having a different susceptibility pattern, or (c) obtained more than 21 days apart. Non-unique isolates were excluded. An episode was defined as polyfungal when more than one species was isolated in blood cultures obtained the same day. The numbers of episodes were centre-based, in accordance with previous Danish candidaemia publications $[7,9,10,22]$. The incidences are defined as number of episodes relative to the number of inhabitants, discharges, or bed days.

Most departments served several hospitals. Four centres used BacT / ALERT (bioMérieux, Marcy l'Etoile, France), one centre used BACTEC (Becton Dickinson, Franklin Lakes, NJ, USA), and the remaining five either changed systems during the study period or used both systems concomitantly (Supplementary Table S1).

\subsection{Susceptibility Testing and FKS Gene Sequence Analysis}

Susceptibility testing was done prospectively for $\geq 98.8 \%$ of the isolates according to EUCAST E.Def 7.3 [23]. Stock solutions ( $5000 \mathrm{mg} / \mathrm{L}$ in dimethyl sulfoxide (DMSO; Sigma-Aldrich, Brøndby, Denmark) were used of the following compounds: fluconazole, voriconazole and amphotericin B (Sigma- Aldrich), anidulafungin (Pfizer A/S, Ballerup, Denmark), and micafungin (Astellas Pharma Inc., Tokyo, Japan; and Molcan Corporation, Toronto, Canada from 15 May 2018). C. parapsilosis ATCC 22019, or C. krusei ATCC 6258, or both were included as quality controls. The final test concentration ranges varied over the years, but the following concentrations were included throughout: amphotericin $B$ $0.016-4 \mathrm{mg} / \mathrm{L}$, anidulafungin $0.008-1 \mathrm{mg} / \mathrm{L}$ (C. dubliniensis: $0.004-1 \mathrm{mg} / \mathrm{L}$ ), micafungin $0.008-1 \mathrm{mg} / \mathrm{L}$, fluconazole $0.125-16 \mathrm{mg} / \mathrm{L}$, and voriconazole $0.03-4 \mathrm{mg} / \mathrm{L}$. Susceptibility classification was performed adopting the current EUCAST clinical breakpoints v. 10.0 [24]. For drug-species combinations without breakpoints, MICs were interpreted as follows. For amphotericin B, the non-species-specific susceptibility breakpoint of $1 \mathrm{mg} / \mathrm{L}$ was used for all species, except $C$. lusitaniae (which is regarded as intrinsically resistant regardless of the MIC due to a high mutation rate and lower amphotericin B cidality [25]). For fluconazole, the EUCAST non-species-specific breakpoints were used (S: $\leq 2$ and R: $>4 \mathrm{mg} / \mathrm{L}$ ) for all Candida spp. For echinocandins against C. dubliniensis specifically, single-centre $99 \%$ wildtype upper limits (WT-UL 99 ) were determined using the ECOFF finder program v. 2.1 [26] and adopted as susceptibility breakpoints (anidulafungin: $\leq 0.03 \mathrm{mg} / \mathrm{L}$ and micafungin: $\leq 0.06 \mathrm{mg} / \mathrm{L}$ ). Finally, established EUCAST ECOFFs were used to determine the proportion of non-wildtype isolates according to the European Committee on Antimicrobial Susceptibility Testing [27].

FKS sequencing was performed as previously described for Candida isolates with an elevated echinocandin MIC [10]. In case of discordant susceptibility classification for anidulafungin and micafungin, the isolate was deemed resistant if $F K S$ sequencing confirmed a known hotspot alteration. Acquired echinocandin resistance rates were determined for C. albicans, C. dubliniensis, C. glabrata, C. krusei, Candida tropicalis, and Candida kefyr, and compared with data from the previous years [10].

\subsection{Population Data}

Annual Danish population data from the first quartile was obtained from dst.dk accessed on 25 May 2021. The total numbers of discharges and bed days among somatic admissions were obtained and accessed on 19 December 2019 from www.esundhed.dk. Furthermore, the microbiologists at the clinical microbiological departments provided data separately from their own centre. Numbers of selected abdominal surgical procedures were available at www.esundhed.dk accessed on 25 May 2021, from the period 2005 to 2018. 
In order to use Poisson regression analysis and compare numbers of episodes in patient groups relative to the population number per year, patients count individually per year and according to patient ID in the current study period.

\subsection{Consumption of Antifungal Compounds}

The antifungal consumption for Denmark was retrieved for primary health care sector and hospital from the website www.medstat.dk, obtained and accessed on 8 July 2020. Global antifungal use for Norway, Sweden, and Finland (DDD/1000 inhabitants/year) was acquired from Grossistbasert legemiddelstatistikk, Folkehelseinstituttet or in English: Norwegian Drug Wholesales Statistics, Norwegian Institute of Public Health-www.fhi.no, obtained and accessed on 21 August 2020; www.socialstyrelsen.se, obtained and accessed on 15 August 2017; and www.firmea.fi, obtained and accessed on 6 September 2020, respectively. Data on antifungal consumption in Sweden were not available for 2017 and 2018, thus the comparison is made only for Denmark, Norway, and Finland for these years.

\subsection{Statistics}

The $\chi^{2}$-test was used when comparing isolate proportions in groups, and Fischer's exact test was used when the expected counts were $<5$. The $\chi^{2}$-test for a trend was used when comparing isolate proportions in a four-period time interval or more than two age groups, using GraphPad Prism v. 8.3.0. (San Diego, CA, USA). A negative binominal dispersion was used when comparing numbers of episodes relative to the number of bed days in the four periods as well as numbers of episodes relative to the numbers of inhabitants for the period 2011 to 2018 using IBM SPSS Statistics v. 26 (Armonk, New York, NY, USA). A Poisson regression analysis was used for numbers of episodes in gender and age groups using IBM SPSS Statistics v. 26.

The study was approved by Compliance at Statens Serum Institut (journal number: 21/00993).

\section{Results}

A total of 1454 unique blood isolates from 1402 unique episodes in 1311 patients were collected in the years 2016 to 2018 (Table 1). Half of the candidaemia cases (52.8\%) involved patients 60-79 years old (Supplementary Table S2). Most episodes occurred in males (60\%) (Table 1). The age and gender group that contained the highest number of isolates $(21.1 \%)$ was males 70-79 years old (Figure 1).

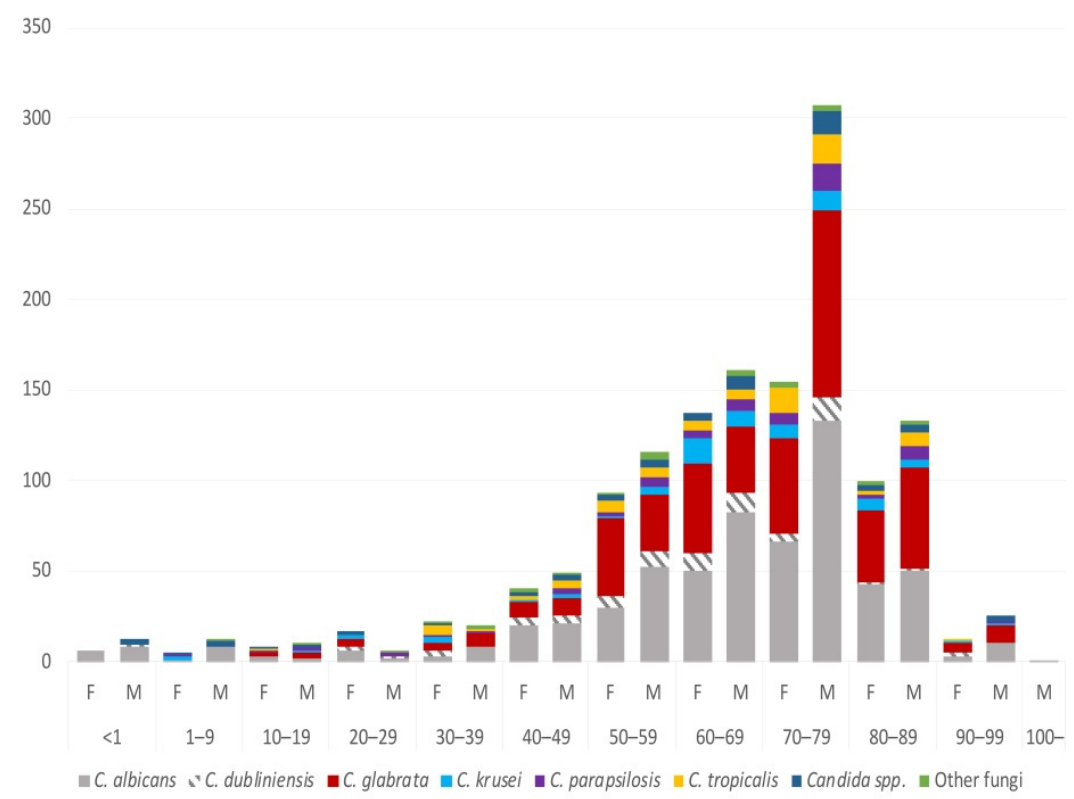

Figure 1. Number of isolates according to age and gender in 2016 to 2018. 
Table 1. Population and patient demographics, episode rates, and species distribution.

\begin{tabular}{|c|c|c|c|c|}
\hline & 2016 & 2017 & 2018 & 2016-2018 \\
\hline Number of isolates & 453 & 482 & 519 & 1454 \\
\hline Number of episodes & 436 & 464 & 502 & 1402 \\
\hline Number of patients & 409 & 432 & 470 & 1311 \\
\hline Median age (range) & $70(0-96)$ & $71(0-102)$ & $69.5(0-96)$ & $70(0-102)$ \\
\hline Number of episodes in & $260 / 176$ & $267 / 197$ & $307 / 195$ & $834 / 568$ \\
\hline males/females (\%) & $(59 / 41)$ & $(58 / 42)$ & $(62 / 38)$ & $(60 / 40)$ \\
\hline Population & $5,707,251$ & $5,748,768$ & $5,781,190$ & $5,745,736.3^{a}$ \\
\hline \multicolumn{5}{|l|}{ Incidences of episodes } \\
\hline Per 100,000 inhabitants & 7.64 & 8.07 & 8.68 & 8.13 \\
\hline Per 1000 discharges & 0.31 & 0.33 & 0.37 & 0.34 \\
\hline Per 10,000 bed days & 1.02 & 1.10 & 1.21 & 1.11 \\
\hline \multicolumn{5}{|l|}{$\begin{array}{l}\text { Number of isolates } \\
\text { (\% of total) }\end{array}$} \\
\hline C. albicans & $195(43 \%)$ & $190(39.4 \%)$ & $227(43.7 \%)$ & $612(42.1 \%)$ \\
\hline C. glabrata & $146(32.2 \%)$ & $167(34.6 \%)$ & $154(29.7 \%)$ & $467(32.1 \%)$ \\
\hline C. dubliniensis & $17(3.8 \%)$ & $27(5.6 \%)$ & $29(5.6 \%)$ & $73(5.0 \%)$ \\
\hline C. tropicalis & $27(6.0 \%)$ & $26(5.4 \%)$ & $22(4.2 \%)$ & $75(5.2 \%)$ \\
\hline C. parapsilosis & $16(3.5 \%)$ & $20(4.1 \%)$ & $26(5.0 \%)$ & $62(4.3 \%)$ \\
\hline C. krusei & $25(5.5 \%)$ & $24(5.0 \%)$ & $24(4.6 \%)$ & $73(5.0 \%)$ \\
\hline Candida spp. ${ }^{\mathrm{b}}$ & $16(3.5 \%)$ & $21(4.4 \%)$ & $28(5.4 \%)$ & $65(4.5 \%)$ \\
\hline Other fungi ${ }^{c}$ & $11(2.4 \%)$ & $7(1.5 \%)$ & $9(1.7 \%)$ & $27(1.9 \%)$ \\
\hline
\end{tabular}

${ }^{a}$ mean population during the three years. ${ }^{b}$ Candida spp.: C. lusitanae $(n=22)$, C. guilliermondii (9), C. kefyr (8), C. orthopsilosis (5), C. metapsilosis (3), C. pelliculosa (3), C. species (3), C. fermentati (2), C. inconspicua (2), C. norvegensis (2), C. utilis (2), C. nivariensis (1), C. pararugosa or Wickerhamiella pararugosa (1), Lodderomyces elongisporus (1), C. eremophila (Pichia kluyveri) (1). ${ }^{\mathrm{c}}$ Other fungi: Cryptococcus neoformans (9), Saccharomyces cerevisiae (7), Magnusiomyces capitatus (formerly known as Geotrichum capitatum) (4), Saccharomyces telluris (1), Cryptococcus albidus (1), Rhodotorula mucilaginosa (1), Fusarium dimerum (1), Fusarium solani (1), Barnettozyma salicaria (formerly known as Pichia salicaria) (1), and mould not further identified due to insufficient growth (1).

\subsection{Incidence}

The incidence was 8.13/100,000 inhabitants in 2016-2018 compared to 8.64, 9.03 and 8.38 per 100,000 inhabitants in the time periods 2004-2007, 2008-2011, and 2012-2015, respectively (Table 1 , Table 2, and Figure 2). The incidence did not decrease significantly from the peak in 2011 to $2018(p=0.08)$. The numbers of episodes relative to the numbers of bed days increased significantly in the four periods $(p<0.001)$. The highest incidences were observed at the extremes of age (Figure 3). Gender-specific incidences were different: there were 9.73/100,000 male inhabitants and 6.56/100,000 female inhabitants in 2016-2018, with a male/female incidence rate ratio (IRR) of 1.666 (95\% CI: 1.655-1.668).

Table 2. Data in a four-period perspective.

\begin{tabular}{|c|c|c|c|c|}
\hline & $2004-2007$ & $2008-2011$ & $2012-2015$ & $2016-2018$ \\
\hline \multicolumn{5}{|l|}{ Incidences of episodes } \\
\hline per 100,000 inhabitants & 8.64 & 9.03 & 8.38 & 8.13 \\
\hline per 1000 discharges & 0.39 & 0.38 & 0.34 & 0.34 \\
\hline per 10,000 bed days & 0.90 & 1.03 & 1.06 & 1.11 \\
\hline \multirow{2}{*}{$\begin{array}{c}\text { Elderly population ( } \geq 70 \text { years) } \\
\text { Numbers of selected surgical procedures } \\
\text { (mean/year) }\end{array}$} & 573,697 & 600,248 & 661,414 & 761,795 \\
\hline & 134,468 & 152,086 & 195,329 & 238,072 \\
\hline $\begin{array}{l}\text { Numbers of admission to the intensive care unit } \\
\text { (mean/year) }\end{array}$ & 11,193 & 11,345 & 12,472 & 12,596 \\
\hline \multicolumn{5}{|l|}{ Susceptibility } \\
\hline Echinocandin acquired resistance rate $(\%)$ & $0(0 / 1294)$ & $0.6(10 / 1581)$ & $1.7(29 / 1754)$ & $1.5(19 / 1295)$ \\
\hline Fluconazole susceptibility rate (\%) & $68.5(972 / 1420)$ & $65.2(1137 / 1745)$ & $60.6(1147 / 1892)$ & $59.0(848 / 1438)$ \\
\hline
\end{tabular}

The number for the elderly population $\geq 70$ years is the mean number per year in the stated period. Numbers of selected surgical procedures and bed days were available at www.esundhed.dk accessed on 25 May 2021. Operations on the digestive tract and spleen, punctures and punctual biopsies/smaller surgeries, and endoscopies were chosen. Numbers stated as " $<5$ " at www.esundhed.dk accessed on 25 May 2021 were not included in the calculations. Numbers of admissions to the intensive care unit were provided by RKKP (Regionernes Kliniske Kvalitetsudviklingsprogram) from the Danish Intensive Database. 
$70 \%$

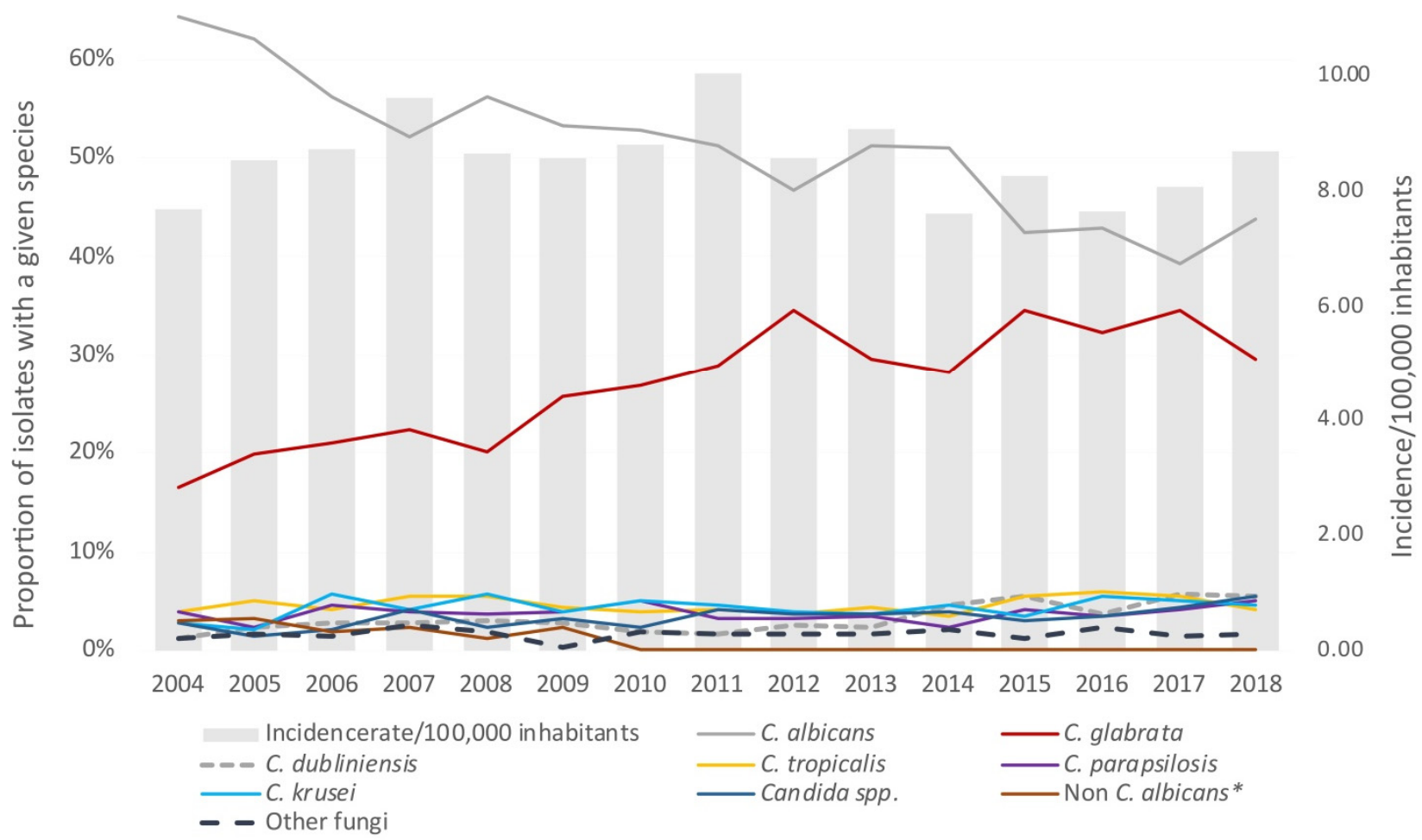

Figure 2. Fungaemia species distribution and incidence per 100,000 inhabitants in 2004 to $2018 .{ }^{*}$ The term non-C. albicans was used from 2004 to 2009.

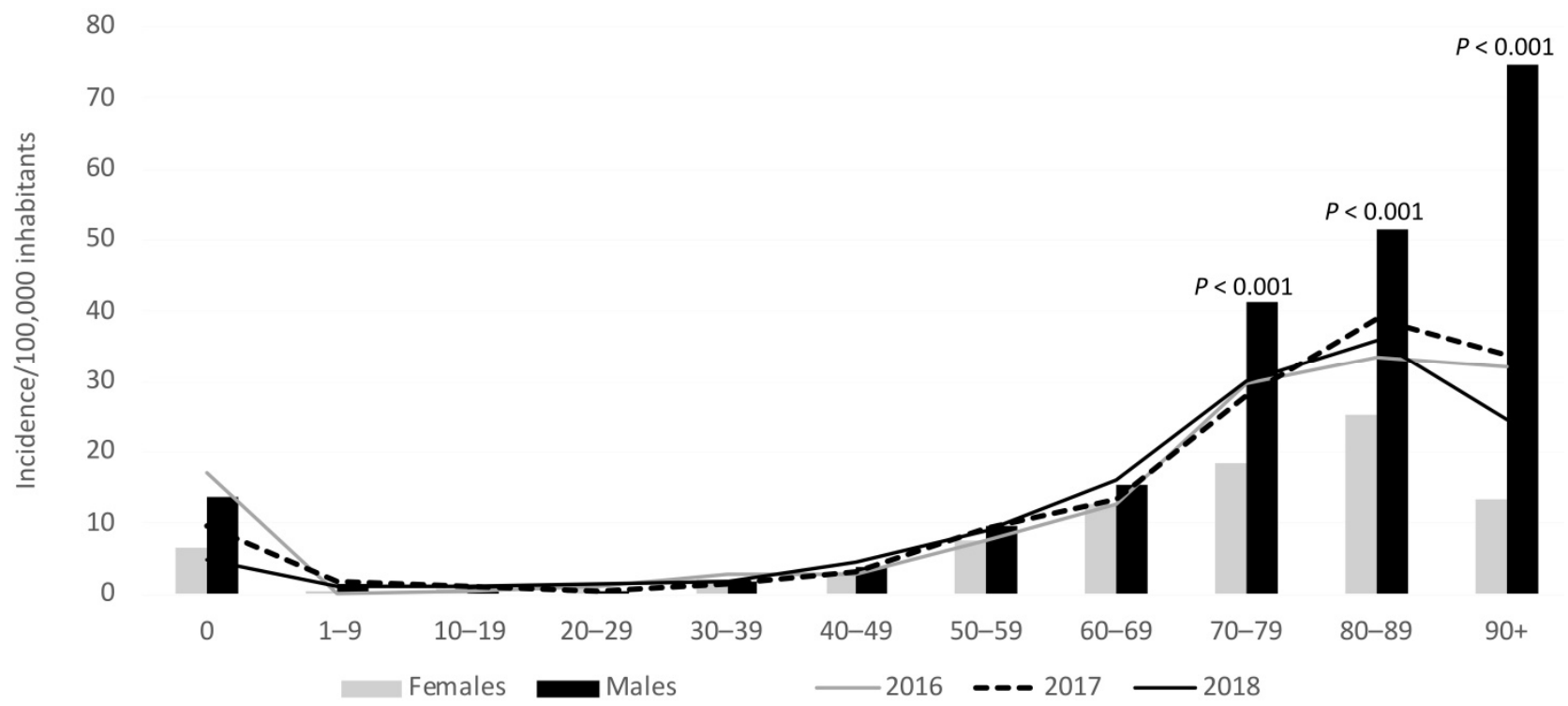

Figure 3. Age- and gender-specific episode rates in 2016-2018 (bars) and age-specific incidences each year (lines). Incidences are determined based on the number of episodes per inhabitants in the specific age and gender groups. Population data for the age group $90+$ are based on the number of inhabitants from 90 years up to 109 years old. The $p$-values are stated when statistically significant between genders in the specific age group. 
The incidence rate was significantly higher in the older age groups for both males (80-89 and $\geq 90$ years) and for females (80-89 years) compared to all other age groups (Figure 3, Supplementary Table S3).

\subsection{Species Distribution}

C. albicans (42.1\%) and C. glabrata (32.1\%) were the two dominant species in 2016-2018. C. albicans accounted for less than $40 \%$ in 2017 (Table 1, Figure 2). C. tropicalis, C. krusei, C. dubliniensis, and C. parapsilosis each accounted for $\leq 5.2 \%$; other Candida species $4.5 \%$; and isolates $(n=27)$ other than Candida accounted for $1.9 \%$ (Table 1, Figure 2). Polyfungal episodes $(n=52)$ accounted for $3.7 \%$ of the episodes and half of these involved C. albicans and C. glabrata ( $n=27,1.9 \%$ of all). Notable differences in the epidemiology were observed between the specific centres (Supplementary Table S1). Comparing the seven centres serving university ( \pm district) hospitals that all had $>100$ (range 149-258) blood-culture isolates, the incidence varied three-fold (5.62-14.6/100,000 inhabitants and 0.59-1.94/10,000 bed days), and the C. albicans and C. glabrata proportions varied $34.4-48.4 \%$ and $24.7-38.0 \%$, respectively.

During 2004-2018 C. albicans decreased (64.4\% to $43.7 \%)$ and C. glabrata increased (16.5\% to 29.7\%) [22], (both $p<0.0001$ compared with 2004-2007, 2008-2011, $2012-2015$, and 2016-2018). Moreover, $C$. dubliniensis and other Candida species increased $(p<0.001$ and $p=0.004$, respectively), whereas the proportions of $C$. krusei, $C$. parapsilosis, and $C$. tropicalis remained stable (Figure 2).

\subsection{Species and Gender}

In 2016-2018 C. albicans was more common in males than females $(44.4 \%$ and $38.8 \%$, $p=0.03)$, and C. glabrata was more common in females than in males ( $35.3 \%$ and $29.9 \%$, $p=0.03)$.

\subsection{Species and Age}

The proportion of $C$. glabrata isolates increased with increasing age group $(p<0.001)$. Of note, $C$. parapsilosis was not detected among patients $<1$ years, and only a single $C$. parapsilosis has been found in this age group (2.4\%) since 2012 as compared to $10(16.9 \%)$ during 2004-2011 ( $p=0.03$ ) (Figure 4). The age-specific species distribution also varied among the centres. The referral hospital Rigshospitalet had the lowest proportion of $C$. glabrata and the highest proportion of patients with candidaemia in the age group below 50 years. Details of blood-culture systems and centre-specific incidences are presented in Supplementary Table S1. 
A

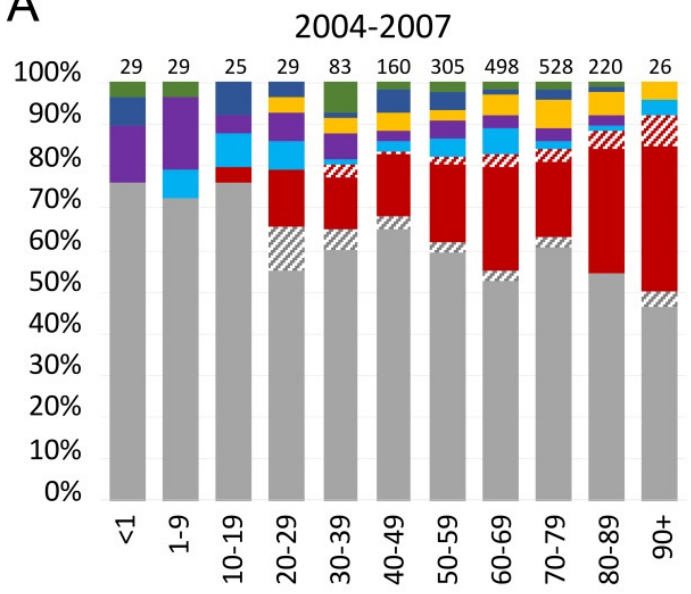

C

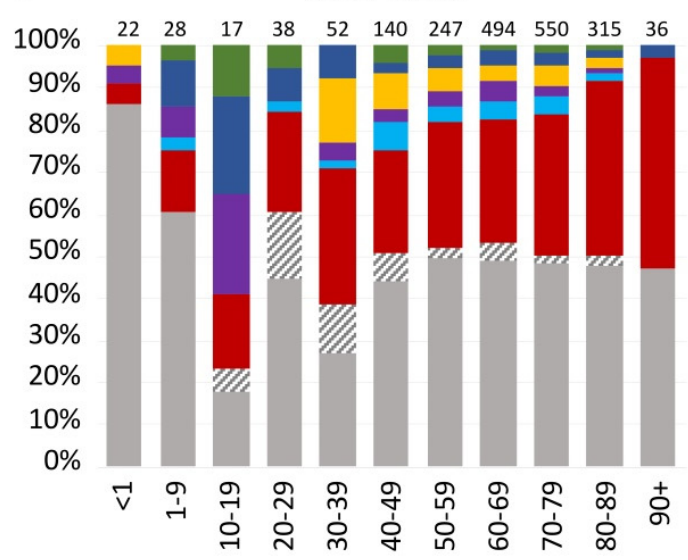

B

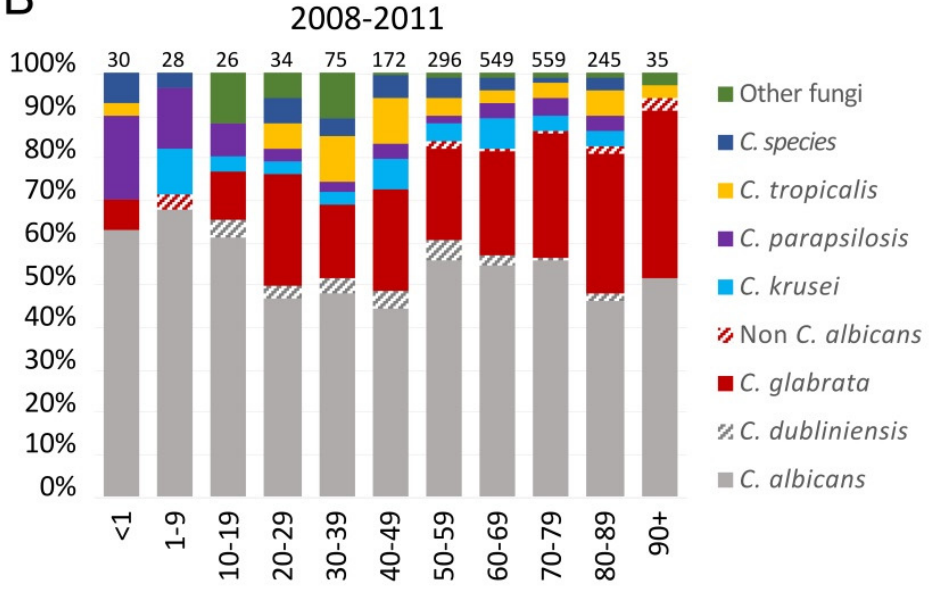

$\mathrm{D}$

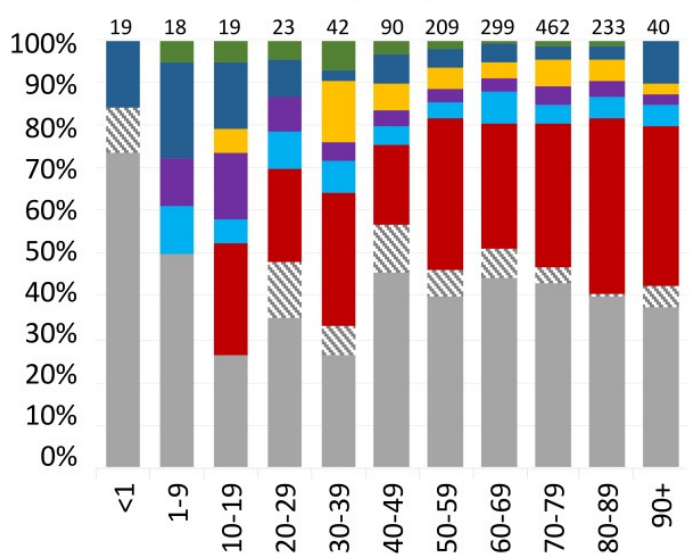

Figure 4. Species distribution in proportions (\%) among age groups (years) in the four periods 2004 to 2007 (A), 2008 to 2011 (B), 2012 to 2015 (C), and 2016 to 2018 (D). Number of total number of isolates within one age group is stated. Data from 2004 to 2015 have previously been published by Astvad et al. [10].

\subsection{Susceptibility}

MICs for the 1439 isolates referred for susceptibility testing are shown in Table 3. Thirteen isolates were not referred, and two isolates were not susceptibility tested, as further detailed in the methods section.

Acquired echinocandin resistance was detected in 19 isolates: 12/460 C. glabrata isolates, 5/72 C. krusei isolates, 1/72 C. dubliniensis, $1 / 608$ C. albicans, $0 / 75$ C. tropicalis, and 0/8 C. kefyr. The acquired echinocandin resistance rate among species that are normally susceptible but in which acquired resistance has previously been reported was 1.5\% $(19 / 1295)$ in 2016-2018, and increased in a four-period perspective $(p<0.001)$. Of the resistant isolates, 16 harboured $F K S$ hot-spot alterations. Six isolates harboured $F K S$ alterations outside the hot-spot regions (Table 4). The echinocandin resistance rate in C. glabrata, specifically, was $2.6 \%(12 / 460)$. Of those $8.3 \%(1 / 12)$ was also fluconazole resistant, but none displayed resistance to amphotericin B. Susceptibility to amphotericin B was overall $99.9 \%$. 
Table 3. Susceptibility table for fungal blood isolates in 2016 to 2018.

\begin{tabular}{|c|c|c|c|c|c|c|c|c|c|c|c|c|c|c|c|c|c|c|c|}
\hline \multirow{2}{*}{$\begin{array}{l}\text { Species and } \\
\text { Compound }\end{array}$} & \multicolumn{13}{|c|}{ Number of Isolates with the Given MIC (mg/L) } & \multicolumn{2}{|l|}{$\mathbf{S}$} & \multirow{2}{*}{$\begin{array}{c}\text { R } \\
\begin{array}{c}\text { Number } \\
\text { of } \\
\text { Isolates }\end{array}\end{array}$} & \multirow{2}{*}{\multicolumn{2}{|c|}{$\begin{array}{c}\begin{array}{c}\text { Non- } \\
\text { Wildtype }\end{array} \\
\begin{array}{c}\text { Number } \\
\text { of } \\
\text { Isolates }\end{array}\end{array}$}} & \multirow[b]{2}{*}{$\%$} \\
\hline & $\leq 0.008$ & 0.016 & 0.03 & 0.06 & 0.125 & 0.25 & 0.5 & 1 & 2 & 4 & 8 & 16 & $\geq 32$ & $\begin{array}{c}\text { Number } \\
\text { of } \\
\text { Isolates }\end{array}$ & $\%$ & & & & \\
\hline \multicolumn{20}{|c|}{ C. albicans $(n=608)$} \\
\hline Amphotericin B & & & & 19 & 186 & 354 & 49 & & & & & & & 608 & $100 \%$ & 0 & 0 & 0 & 0 \\
\hline Anidulafungin & 577 & 29 & 2 & & & & & & & & & & & 608 & $100 \%$ & 0 & 0 & 0 & 0 \\
\hline Micafungin & 362 & 228 & 17 & $\underline{1}$ & & & & & & & & & & 607 & $99.8 \%$ & 1 & $0.2 \%$ & 18 & $3.0 \%$ \\
\hline Voriconazole & & & 602 & 2 & & & & $\underline{1}$ & $\underline{1}$ & & $\underline{2}$ & & & 604 & $99.3 \%$ & 4 & $0.7 \%$ & 6 & $1.0 \%$ \\
\hline \multicolumn{20}{|c|}{ C. dubliniensis $(n=72)$} \\
\hline Amphotericin B & & 6 & 28 & 28 & 10 & & & & & & & & & 72 & $100 \%$ & 0 & 0 & 0 & 0 \\
\hline Anidulafungin & $37 *$ & 29 & 5 & & & $\underline{1}$ & & & & & & & & 71 & $98.6 \%$ & 1 & $1.4 \%$ & ND & ND \\
\hline Micafungin & 11 & 31 & 27 & 2 & & & & & $\underline{1}$ & & & & & 71 & $98.6 \%$ & 1 & $1.4 \%$ & ND & ND \\
\hline Fluconazole & & & & & 33 & 28 & 7 & & & 1 & & $\underline{1}$ & $\underline{2}$ & 68 & $94.4 \%$ & 3 & $4.2 \%$ & 4 & $5.6 \%$ \\
\hline Voriconazole & & & 69 & & 2 & 1 & & & & & & & & 69 & $95.8 \%$ & 0 & 0 & 3 & $4.2 \%$ \\
\hline \multicolumn{20}{|c|}{ C. glabrata $(n=460)$} \\
\hline Amphotericin B & & & 3 & 11 & 58 & 239 & 148 & 1 & & & & & & 460 & $100 \%$ & 0 & 0 & 0 & 0 \\
\hline Micafungin & 90 & 247 & 113 & $\underline{5}$ & $\underline{2}$ & & $\underline{2}$ & $\overline{1}$ & & & & & & 450 & $97.8 \%$ & 10 & $2.2 \%$ & 10 & $2.2 \%$ \\
\hline Fluconazole & & & & & & & $\overline{2}$ & $\overline{10}$ & 142 & 223 & 28 & 6 & 49 & 0 & 0 & 49 & $10.7 \%$ & 49 & $10.6 \%$ \\
\hline Voriconazole & & & 53 & 252 & 92 & 9 & 5 & 11 & 26 & 10 & 2 & & - & IE & IE & IE & IE & 38 & $8.3 \%$ \\
\hline \multicolumn{20}{|l|}{ C. $k$ rusei $(n=72)$} \\
\hline Amphotericin B & & & & & & 1 & 47 & 24 & & & & & & 72 & $100 \%$ & 0 & 0 & 0 & 0 \\
\hline Anidulafungin & & 16 & 38 & 15 & $\underline{2}$ & & $\underline{1}$ & & & & & & & 69 & $95.8 \%$ & 3 & $4.2 \%$ & 3 & $4.2 \%$ \\
\hline Micafungin & & & & 7 & 54 & 7 & $\overline{3}$ & & & & 1 & & & IE & IE & IE & IE & 4 & $5.6 \%$ \\
\hline Fluconazole & & & & & & & & & & & $\underline{2}$ & $\underline{16}$ & $\underline{54}$ & 0 & 0 & 72 & $100 \%$ & ND & ND \\
\hline Voriconazole & & & & & 16 & 36 & 13 & 5 & 1 & & 1 & & & IE & IE & IE & IE & 2 & $2.8 \%$ \\
\hline \multicolumn{20}{|c|}{$\begin{array}{l}\text { C. parapsilosis sensu } \\
\text { stricto }(n=61)\end{array}$} \\
\hline Amphotericin B & & & & & 1 & 18 & 41 & 1 & & & & & & 61 & $100 \%$ & 0 & 0 & 0 & 0 \\
\hline Anidulafungin & & & & & & 1 & 20 & 21 & 15 & 4 & & & & 61 & $100 \%$ & 0 & 0 & 0 & 0 \\
\hline Micafungin & & & & & & 1 & 2 & 27 & 30 & $\underline{1}$ & & & & 60 & $98.4 \%$ & 1 & $1.6 \%$ & 1 & $1.6 \%$ \\
\hline Fluconazole & & & & & & 1 & 34 & 20 & 5 & & & & $\underline{1}$ & 60 & $98 . \%$ & 1 & $1.6 \%$ & 1 & $1.6 \%$ \\
\hline Voriconazole & & & 58 & 2 & & & $\underline{1}$ & & & & & & & 60 & $98.4 \%$ & 1 & $1.6 \%$ & 1 & $1.6 \%$ \\
\hline
\end{tabular}


Table 3. Cont.

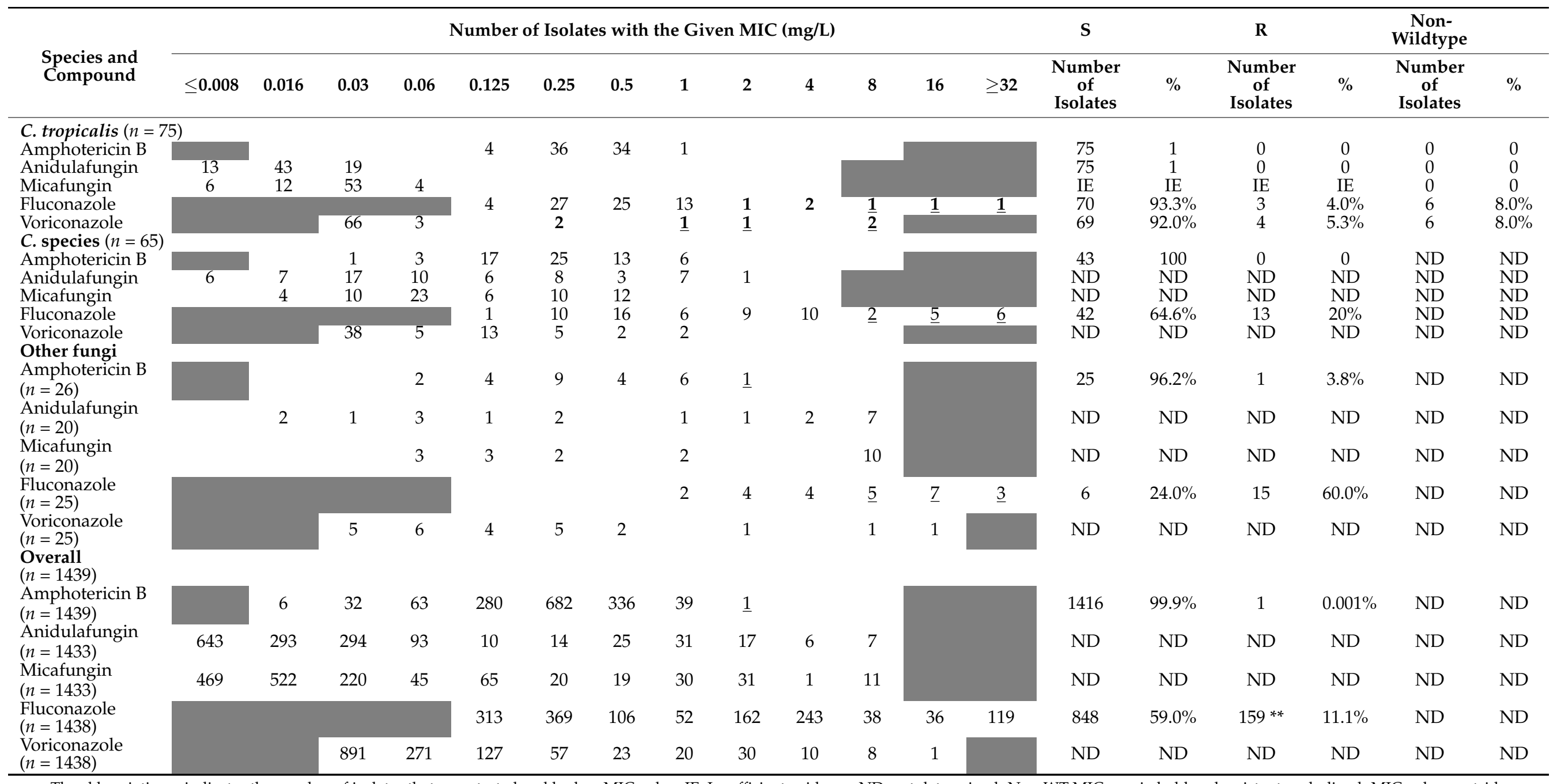

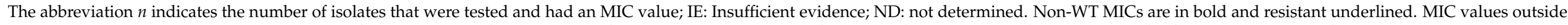

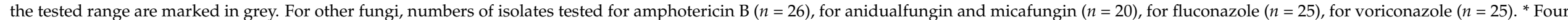

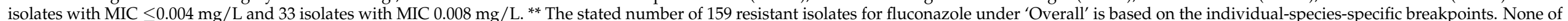

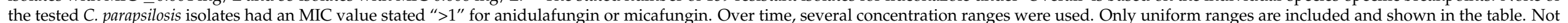
all isolates were tested for all antifungal agents if known to be intrinsically resistant. 
Table 4. Identified FKS amino acid (AA) alterations. Unless stated otherwise, the detected alterations are known to be associated with echinocandin resistance.

\begin{tabular}{|c|c|c|c|}
\hline Species $(n)$ & Echinocandin Resistant $(n)$ & FKS Alteration & Hotspot (HS) Location \\
\hline \multicolumn{4}{|l|}{$\begin{array}{l}\text { Isolates with hotspot } \\
\text { alterations }\end{array}$} \\
\hline C. glabrata (1) & Yes & F625S & Fks1 \\
\hline C. glabrata (2) & Yes & L630Q and S663F & Fks1and Fks2, respectively \\
\hline C. glabrata (3) & Yes & F659S & Fks2 \\
\hline C. glabrata (1) & Yes & F659del & Fks2 \\
\hline C. glabrata (1) & Yes & L662W & Fks2 \\
\hline C. glabrata (3) & Yes & $\mathrm{S} 663 \mathrm{~F}$ & Fks2 \\
\hline C. glabrata (1) & Yes & S663P & Fks2 \\
\hline C. krusei (2) & Yes & $\mathrm{S} 659 \mathrm{~S} / \mathrm{F}$ & Fks1 \\
\hline C. krusei (1) & Yes & S659F & Fks1 \\
\hline C. dubliniensis (1) & Yes & S645P & Fks1 \\
\hline \multicolumn{4}{|c|}{$\begin{array}{l}\text { Isolates with alterations } \\
\text { outside the hotspots }\end{array}$} \\
\hline C. krusei (4) & Yes (2) No (2) & L701M* & Fks1; 38 AA after HS1 \\
\hline C. albicans (1) & Yes & $\mathrm{P} 1354 \mathrm{P} / \mathrm{S} * *$ & Fks1; 3 AA before HS2 \\
\hline C. lusitaniae (1) & No & $(\mathrm{H} 657 \mathrm{Y} / \mathrm{L} 1243 \mathrm{~F} / \mathrm{I} 1283 \mathrm{~V})^{* *}$ & $\begin{array}{c}\text { Fks } 1 ; 15 \text { AA after HS1; } 105 \text { AA } \\
\text { before HS2 and } 65 \text { AA before HS2 }\end{array}$ \\
\hline
\end{tabular}

${ }^{*}$ L701M is located 38 AA after hotspot 1 and is not associated with echinocandin resistance. ${ }^{* *}$ Unknown association to echinocandin resistance.

Acquired fluconazole resistance accounted for 4.6\% (59/1276) among the most common species that are normally either $\mathrm{S}$ or I to fluconazole. In detail, acquired fluconazole resistance was detected in $0.5 \%(3 / 608)$ C. albicans, $4.2 \%(3 / 72)$ C. dubliniensis, $10.7 \%$ (49/460) C. glabrata, 1.6\% (1/61) C. parapsilosis, and 4.0\% (3/75) C. tropicalis. Combined fluconazole and echinocandin resistance was found in one C. albicans, one C. glabrata, and five C. krusei. Voriconazole resistance/non-wild-type phenotype was detected in 3.7\% (47/1276) of the same most common species including $0.7 \%(4 / 608)$ C. albicans, $0.0 \%(0 / 72)$ C. dubliniensis, 8.3\% (38/460) C. glabrata, 5.3\% (4/75) C. tropicalis, and 1.6\% (1/61) C. parapsilosis. The proportion of fluconazole-susceptible isolates (at standard dosing) decreased to $59.0 \%(848 / 1438)$ in a four-period perspective from $68.5 \%(972 / 1420), 65.2 \%(1137 / 1745)$, and $60.6 \%(1147 / 1892)$ in 2004-2007, 2008-2011, and 2012-2015, respectively $(p<0.001$, Table 2).

\subsection{Antifungal Consumption}

The consumption of the antifungal agents amphotericin B, fluconazole, voriconazole, and posaconazole in Denmark peaked in the years 2012 to 2014. The consumption of echinocandins has increased in Danish hospitals since 2004 and was highest in 2018 (3.3 DDDs/1000 inhabitants/year) (Figure 5 and Supplementary Figure S1). The total consumption of fluconazole was highest in Denmark during 2012-2015 and decreased during the current three-year study period to 172,160 , and 155 DDDs/1000 inhabitant/year, respectively (Figure 5). During 2016-2018, 71\% (1,988,000/2,803,000 DDD) of the total fluconazole use was prescribed in the primary healthcare sector, including $74 \%(1,462,000 / 1,978,000$ DDDs) prescribed in women.

From a Nordic perspective, the consumption of echinocandins was comparable to that in the other Nordic countries. The consumption of fluconazole and posaconazole remained notably larger in Denmark than in the other Nordic countries, and the consumption of voriconazole and itraconazole was larger in Denmark than in Sweden and Norway (Figure 5 and Supplementary Figure S1). 
A

Echinocandins $0.5-1 \mathrm{~g} / \mathrm{DDD}$

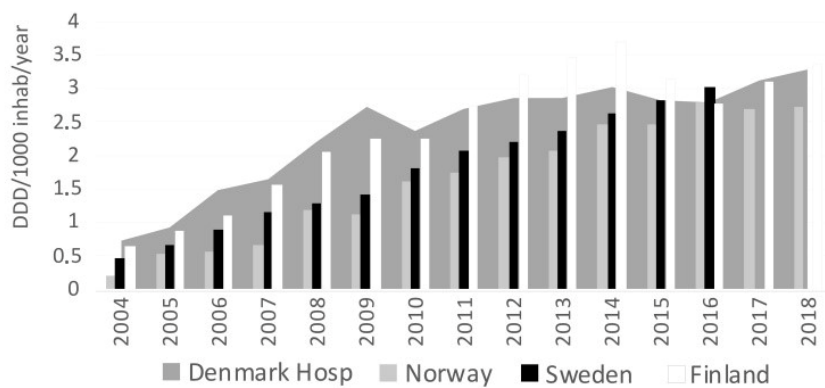

C

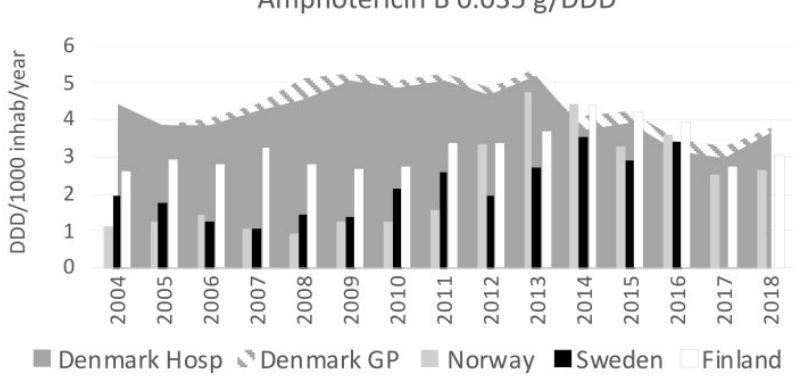

B

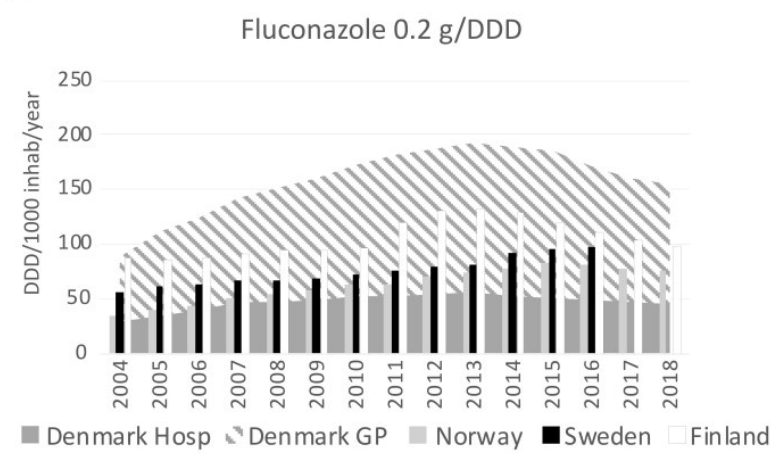

D

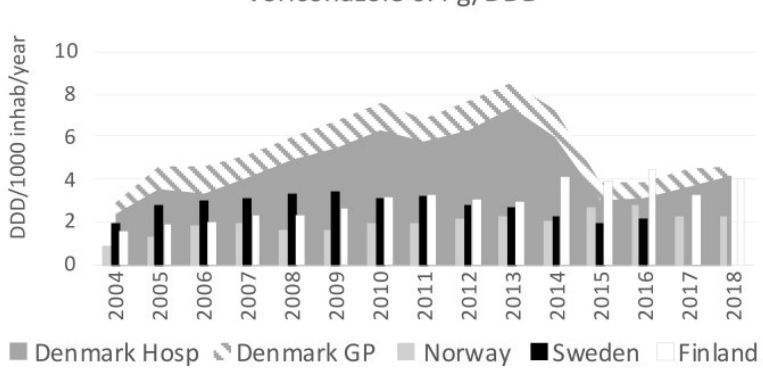

Figure 5. Annual consumption of selected antifungal compounds ((A) Echinocandins, (B) Fluconazole, (C) Amphotericin B, (D) voriconazole) shown in DDDs per 1000 inhabitants per year in 2004 to 2018. For Denmark the usage is divided into hospital use (Hosp) and general practitioner use (GP). Data from 2004 to 2015 were also shown in the surveillance by Astvad et al. [10].

\section{Discussion}

We previously reported an increase in incidence up until 2011 and a slight decrease in 2012-2015 [10] but this trend did not seem to continue during 2016-2018. In contrast, the incidence appears to have stabilised. Consequently, Denmark remained a high incidence country from both Nordic and global perspectives, with an incidence similar to the one found in the CDC's Emerging Infections Program US [14-18,28]. The species distribution, however, continued to shift towards a higher proportion of $C$. glabrata and a lower proportion of C. albicans (even below $40 \%$ in 2017). A C. albicans proportion below $40 \%$ has been reported in the US and South America [28-32], but no other Nordic country has reported a C. albicans proportion below $50 \%[14,16,17,33]$. This change in species distribution was the main cause of the observed decrease in overall fluconazole susceptibility, yet acquired fluconazole and voriconazole resistances were found in $4.6 \%$ and $3.7 \%$, respectively, of the normally susceptible common Candida spp. isolates. The echinocandin resistance rate increased in a four-period perspective (where also the echinocandin use increased), but remained stable during 2012-2018 and less common than acquired resistance to fluconazole [10]. C. glabrata was confirmed as the species with the highest rates of acquired echinocandin, fluconazole, and voriconazole resistance as also found elsewhere $[14,28,34]$. Of note, no cases involving C. auris were detected in Denmark during the observation period.

Candidaemia remained most frequent in males in accordance with previous findings globally $[2,9,10,14-16,33,35-42]$. The median age (70 years) was slightly higher but nevertheless in accordance with previous studies in Denmark, other Nordic countries (64-69 years) and elsewhere (all above 60 years) [10,14,16,31,33,35,37-39,42]. The incidence was highest among males in the age group $\geq 90$ years, and thus later in life than previously [10]. Since the surveillance programme was initiated, life expectancy has increased by 3.6 and 2.7 years for Danish males and females, respectively, which may be part of the 
explanation for the increase in median age (life expectancy—Statistics Denmark). Moreover, an increasing number of surgical procedures and a minor increase in number of admissions to the ICU in the elderly age groups (www.esundhed.dk/Registre accessed on 31 March 2021 and Regionernes Kliniske Kvalitetsudviklingsprogram from the Danish Intensive Database provided 8 June 2021, respectively) suggest that more intensive management strategies are currently offered to the elderly population.

The proportion of C. glabrata isolates increased over time, with age, and was still most common in females [10]. Underlying drivers may be the growing elderly population and a high azole use in Denmark, which remained higher than in the other Nordic countries, and which in the primary health care sector is three times higher in females than in males. C. parapsilosis was not detected in children of less than one year of age during the current 3-year surveillance, and number of isolates was found to be significantly less common in comparing the periods 2012-2018 with 2004-2011. This was somewhat surprising as $C$. parapsilosis historically has been the second most common species in this age group in Denmark and elsewhere $[6,9,22,43,44]$. A recent European paediatric study found geographical differences in incidences of $C$. parapsilosis with the highest incidence in Southern Europe [44]. It is unknown whether these differences over time and between countries are potentially related to differences in infection control practices, use of prophylaxis, or composition of the normal colonising flora.

This study has strengths and limitations. The major strength is that it is population based, nationwide, and includes 15 years of continued surveillance. A limitation is the lack of clinical data and patient-specific antifungal medication. Moreover, differences over time and among centres in blood-culture practices (blood-culture system and sample volume) and antifungal prophylaxis may impact blood-culture sensitivity overall and for the individual species differentially [8]. Another potential caveat is that patients' episodes are counted twice when transferred between centres and when blood culture is positive at both sites, in order to allow centre-specific incidence comparisons of the candidaemia burden. However, since the initiation of the nationwide surveillance, the number of clinical microbiological departments have been reduced-potentially leading to fewer transfers between centres and thus fewer cases being counted twice. Moreover, the number of transfer cases was limited (19 (1.4\%) episodes), resulting in a corrected nationwide incidence of 8.02 rather than $8.13 / 100,000$ inhabitants if transferred cases were omitted, a difference that does not affect the overall findings and conclusions of the study.

In conclusion, we found a stable incidence of fungaemia since the peak in 2011 with a continued shift in species proportion towards C. glabrata, a decreasing overall azole susceptibility rate and increase in acquired echinocandin and azole resistance, especially in C. glabrata. This leads to challenges in management of candidaemia since echinocandin treatment in some cases is inappropriate and de-escalation to fluconazole less often possible. This highlights the need for antifungal stewardship and new antifungal agents with alternative targets. Notable differences were found in comparing the epidemiology between the centres, illustrating the importance of following the local epidemiology.

Supplementary Materials: The following are available online at https:/ /www.mdpi.com/article/10 .3390/jof7060491/s1. Table S1: Centre based data. Species distribution, blood culture systems and episode rates at the ten clinical microbiological departments in 2016 to 2018. Table S2: Number of patients related to age groups. Table S3: P-values for comparisons of episodes in relation to number of inhabitants in patient groups. Figure S1: Annual consumption of itraconazole and posaconazole.

Author Contributions: Conceptualization, M.C.A.; methodology, M.C.A., K.A., M.R. and R.K.H.; formal analysis, M.R. and K.A.; investigation, M.R., K.A. and M.C.A.; datacuration, M.R., K.A. and R.D.; writing—original draft preparation, M.R., K.A. and M.C.A.; writing review and editing, M.C.A., K.A., H.K.J., H.C.S., F.R., J.D.K., R.D., B.L.R., V.S.A., L.K., J.B.G., J.K.M., E.D. and T.S.S.; visualization, M.C.A. and K.A.; supervision, M.C.A. and K.A.; project administration, M.R., R.D., K.A. and M.C.A. All authors have read and agreed to the published version of the manuscript.

Funding: This study did not receive external finding. 
Institutional Review Board Statement: The study was approved by Compliance at Statens Serum Institut journal number: 21/00993.

Informed Consent Statement: It is a data-based surveillance study. Informed consent was not necessary for this type of study.

Data Availability Statement: Data are only available for research upon reasonable request to Statens Serum Institut and within the framework of the Danish data protection legislation.

Acknowledgments: We acknowledge the laboratory staff at Statens Serum Institut and all the clinical microbiological departments. Results were presented in part at the 9th Trends in Medical Mycology as an abstract and a poster. Part of the results have also been summarised in the annual DANMAP 2018 report.

Conflicts of Interest: Outside the study the authors declare the following potential conflicts of interest: M.R.: has over the past 5 years received research grants and travel grants from Gilead. K.A.: has, over the past 5 years, received a personal speaker fee from Pfizer and travel grants from Pfizer and Gilead. H.K.J., H.C.S., F.R., J.D.K., R.D., B.L.R., V.S.A., L.K., J.K.M., E.D., T.S.: No conflicts of interest. R.K.H.: has over the past 5 years received unrestricted research grants and travel grants from Gilead. J.B.G.: has over the past 5 years received a personal speaker fee from MSD and Gilead and travel grants from Gilead and Roche. M.C.A.: has, over the past 5 years, received research grants/contract work (paid to the SSI) from Amplyx, Basilea, Cidara, F2G, Gilead, Novabiotics, Scynexis and T2Biosystems and speaker honoraria (personal fee) from Astellas, Chiesi, Gilead, MSD, and SEGES. She is the current chairman of the EUCAST-AFST.

\section{References}

1. Kullberg, B.J.; Arendrup, M.C. Invasive Candidiasis. N. Engl. J. Med. 2015, 373, 1445-1456. [CrossRef]

2. Lausch, K.R.; Søgaard, M.; Rosenvinge, F.S.; Johansen, H.K.; Boysen, T.; Røder, B.; Mortensen, K.L.; Nielsen, L.; Olesen, B.; Leitz, C.; et al. High incidence of candidaemia in a nationwide cohort: Underlying diseases, risk factors and mortality. Int. J. Infect. Dis. 2018, 76, 58-63. [CrossRef]

3. Behandlingsvejledning Inklusiv Lxgemiddelrekommandation for Systemisk Antimykotisk Behandling, version 2; Rådet Anvendelse af Dyr Sygehusmedicin: Denmark, 2016; pp. 1-19.

4. Cornely, O.A.; Bassetti, M.; Calandra, T.; Garbino, J.; Kullberg, B.J.; Lortholary, O.; Meersseman, W.; Akova, M.; Arendrup, M.C.; Arikan-Akdagli, S.; et al. ESCMID guideline for the diagnosis and management of Candida diseases 2012: Non-neutropenic adult patients. Clin. Microbiol. Infect. 2012, 18 (Suppl. 7), 19-37. [CrossRef]

5. Pappas, P.G.; Kauffman, C.A.; Andes, D.R.; Clancy, C.J.; Marr, K.A.; Ostrosky-Zeichner, L.; Reboli, A.C.; Schuster, M.G.; Vazquez, J.A.; Walsh, T.J.; et al. Clinical Practice Guideline for the Management of Candidiasis: 2016 Update by the Infectious Diseases Society of America. Clin. Infect. Dis. 2016, 62, e1-e50. [CrossRef] [PubMed]

6. Arendrup, M.C.; Fuursted, K.; Gahrn-Hansen, B.; Schønheyder, H.C.; Knudsen, J.D.; Jensen, I.M.; Bruun, B.; Christensen, J.J.; Johansen, H.K. Semi-national surveillance of fungaemia in Denmark 2004-2006: Increasing incidence of fungaemia and numbers of isolates with reduced azole susceptibility. Clin. Microbiol. Infect. 2008, 14, 487-494. [CrossRef]

7. Arendrup, M.C.; Fuursted, K.; Gahrn-Hansen, B.; Jensen, I.M.; Knudsen, J.D.; Lundgren, B.; Schønheyder, H.C.; Tvede, M. Seminational surveillance of fungemia in Denmark: Notably high rates of fungemia and numbers of isolates with reduced azole susceptibility. J. Clin. Microbiol. 2005, 43, 4434-4440. [CrossRef] [PubMed]

8. $\quad$ Arendrup, M.C.; Sulim, S.; Holm, A.; Nielsen, L.; Nielsen, S.D.; Knudsen, J.D.; Drenck, N.E.; Christensen, J.J.; Johansen, H.K. Diagnostic issues, clinical characteristics, and outcomes for patients with fungemia. J. Clin. Microbiol. 2011, 49, $3300-3308$. [CrossRef] [PubMed]

9. Arendrup, M.C.; Dzajic, E.; Jensen, R.H.; Johansen, H.K.; Kjældgaard, P.; Knudsen, J.D.; Kristensen, L.; Leitz, C.; Lemming, L.E.; Nielsen, L.; et al. Epidemiological changes with potential implication for antifungal prescription recommendations for fungaemia: Data from a nationwide fungaemia surveillance programme. Clin. Microbiol. Infect. 2013, 19, E343-E353. [CrossRef]

10. Astvad, K.M.T.; Johansen, H.K.; Røder, B.L.; Rosenvinge, F.S.; Knudsen, J.D.; Lemming, L.; Schønheyder, H.C.; Hare, R.K.; Kristensen, L.; Nielsen, L.; et al. Update from a 12-year nationwide fungemia surveillance: Increasing intrinsic and acquired resistance causes concern. J. Clin. Microbiol. 2018, 56, e01564-17. [CrossRef]

11. Arendrup, M.C.; Perlin, D.S. Echinocandin resistance: An emerging clinical problem? Curr. Opin. Infect. Dis. 2014, $27,484-492$. [CrossRef]

12. Pristov, K.E.; Ghannoum, M.A. Resistance of Candida to azoles and echinocandins worldwide. Clin. Microbiol. Infect. 2019, 25, 792-798. [CrossRef] [PubMed]

13. Perlin, D.S. Mechanisms of echinocandin antifungal drug resistance. Ann. N. Y. Acad. Sci. 2015, 1354, 1-11. [CrossRef]

14. Hesstvedt, L.; Gaustad, P.; Andersen, C.T.; Haarr, E.; Hannula, R.; Haukland, H.H.; Hermansen, N.O.; Larssen, K.W.; Mylvaganam, H.; Ranheim, T.E.; et al. Twenty-two years of candidaemia surveillance: Results from a Norwegian national study. Clin. Microbiol. Infect. 2015, 21, 938-945. [CrossRef] [PubMed] 
15. Sandven, P.; Bevanger, L.; Digranes, A.; Haukland, H.H.; Mannsåker, T.; Gaustad, P. Candidemia in Norway (1991 to 2003 ): Results from a nationwide study. J. Clin. Microbiol. 2006, 44, 1977-1981. [CrossRef]

16. Asmundsdottir, L.R.; Erlendsdottir, H.; Gottfredsson, M. Nationwide study of candidemia, antifungal use, and antifungal drug resistance in Iceland, 2000 to 2011. J. Clin. Microbiol. 2013, 51, 841-848. [CrossRef]

17. Klingspor, L.; Ullberg, M.; Rydberg, J.; Kondori, N.; Serrander, L.; Swanberg, J.; Nilsson, K.; Bengtén, C.J.; Johansson, M.; Granlund, M.; et al. Epidemiology of fungaemia in Sweden: A nationwide retrospective observational survey. Mycoses 2018, 61, 777-785. [CrossRef]

18. Ericsson, J.; Chryssanthou, E.; Klingspor, L.; Johansson, A.G.; Ljungman, P.; Svensson, E.; Sjölin, J. Candidaemia in Sweden: A nationwide prospective observational survey. Clin. Microbiol. Infect. 2013, 19, E218-E221. [CrossRef]

19. Hesstvedt, L.; Arendrup, M.C.; Poikonen, E.; Klingpor, L.; Friman, V.; Nordøy, I. Differences in epidemiology of candidaemia in the Nordic countries-what is to blame? Mycoses 2017, 60, 11-19. [CrossRef] [PubMed]

20. Jensen, J.U.S.; Hein, L.H.; Lundgren, B.; Bestle, M.H.; Mohr, T.; Andersen, M.H.; Løken, J.; Tousi, H.; Søe-Jensen, P.; Lauritsen, A.Ø.; et al. Invasive Candida infections and the harm from antibacterial drugs in critically ill patients: Data from a randomized, controlled trial to determine the role of ciprofloxacin, piperacillin-tazobactam, meropenem, and cefuroxime. Crit. Care Med. 2015, 43, 594-602. [CrossRef]

21. Normand, A.C.; Becker, P.; Gabriel, F.; Cassagne, C.; Accoceberry, I.; Gari-Toussaint, M.; Hasseine, L.; De Geyter, D.; Pierard, D.; Surmont, I. Validation of a new web application for identification of fungi by use of matrix-assisted laser desorption ionization-time of flight mass spectrometry. J. Clin. Microbiol. 2017, 55, 2661-2670. [PubMed]

22. Arendrup, M.C.; Bruun, B.; Christensen, J.J.; Fuursted, K.; Johansen, H.K.; Kjældgaard, P.; Knudsen, J.D.; Kristensen, L.; Møller, J.; Nielsen, L.; et al. National Surveillance of Fungemia in Denmark (2004 to 2009). J. Clin. Microbiol. 2011, 49, 325-334. [CrossRef] [PubMed]

23. Arendrup, M.C.; Cuenca-Estrella, M.; Lass-Flörl, C.; Hope, W. EUCAST technical note on the EUCAST definitive document EDef 7.2: Method for the determination of broth dilution minimum inhibitory concentrations of antifungal agents for yeasts EDef 7.2 (EUCAST-AFST)*. Clin. Microbiol. Infect. 2012, 18, E246-E247. [CrossRef] [PubMed]

24. Arendrup, M.C.; Friberg, N.; Mares, M.; Kahlmeter, G.; Meletiadis, J.; Guinea, J. How to: Interpret MICs of antifungal compounds according to the revised clinical breakpoints v. 10.0 European committee on antimicrobial susceptibility testing (EUCAST). Clin. Microbiol. Infect. 2020, 26, 1464-1472. [CrossRef]

25. Atkinson, B.J.; Lewis, R.E.; Kontoyiannis, D.P. Candida lusitaniae fungemia in cancer patients: Risk factors for amphotericin B failure and outcome. Med. Mycol. 2008, 46, 541-546. [CrossRef] [PubMed]

26. Turnidge, J.; Kahlmeter, G.; Kronvall, G. Statistical characterisation of bacterial wild-type MIC value distributions and the determination of epidemiological cut-off values. Clin. Microbiol. Infect. 2006, 12, 418-425. [CrossRef] [PubMed]

27. European Committee on Antimicrobial Susceptibility Testing. Overview of Antifungal ECOFFs and Clinical Breakpoints for Yeasts, Moulds and Dermatophytes Using the European Committee on Antimicrobial Susceptibility Testing Overview of Antifungal ECOFFs and Clinical Breakpoints for Yeasts, Moulds and Overv Antifung ECOFFs Clin Break Yeasts, Mould Dermatophytes Using EUCAST E.Def 7.3, E.Def 9.3 E.Def 11.0 procedures. Version 2. 2020. Available online: http:/ / www.eucast.org (accessed on 25 May 2021).

28. Toda, M.; Williams, S.R.; Berkow, E.L.; Farley, M.M.; Harrison, L.H.; Bonner, L.; Marceaux, K.M.; Hollick, R.; Zhang, A.Y.; Schaffner, W.; et al. Population-Based Active Surveillance for Culture-Confirmed Candidemia-Four Sites, United States, 2012-2016. MMWR Surveill. Summ. 2019, 68, 1-15. [CrossRef]

29. Santolaya, M.E.; Thompson, L.; Benadof, D.; Tapia, C.; Legarraga, P.; Cortés, C.; Rabello, M.; Valenzuela, R.; Rojas, P.; Rabagliati, R. A prospective, multi-center study of candida bloodstream infections in Chile. PLoS ONE 2019, 14, e0212924. [CrossRef] [PubMed]

30. Tsay, S.V.; Mu, Y.; Williams, S.; Epson, E.; Nadle, J.; Bamberg, W.M.; Barter, D.M.; Johnston, H.L.; Farley, M.M.; Harb, S.; et al. Burden of Candidemia in the United States, 2017. Clin. Infect. Dis. 2020, 71, e449-e453. [CrossRef]

31. Zhang, A.Y.; Shrum, S.; Williams, S.; Petnic, S.; Nadle, J.; Johnston, H.; Barter, D.; VonBank, B.; Bonner, L.; Hollick, R.; et al. The Changing Epidemiology of Candidemia in the United States: Injection Drug Use as an Increasingly Common Risk Factor-Active Surveillance in Selected Sites, United States, 2014-2017. Clin. Infect. Dis. 2019, 71, 1732-1737. [CrossRef]

32. Doi, A.M.; Pignatari, A.C.C.; Edmond, M.B.; Marra, A.R.; Camargo, L.F.A.; Siqueira, R.A.; da Mota, V.P.; Colombo, A.L. Epidemiology and Microbiologic Characterization of Nosocomial Candidemia from a Brazilian National Surveillance Program. PLoS ONE 2016, 11, e0146909. [CrossRef]

33. Ala-Houhala, M.; Valkonen, M.; Kolho, E.; Friberg, N.; Anttila, V.J. Clinical and microbiological factors associated with mortality in candidemia in adult patients 2007-2016. Infect. Dis. 2019, 51, 824-830. [CrossRef] [PubMed]

34. Public Health England. Laboratory surveillance of candidaemia in England, Wales and Northern Ireland: 2018. Health Prot. Rep. 2019, 9, 13 .

35. Hesstvedt, L.; Gaustad, P.; Müller, F.; Torp Andersen, C.; Brunborg, C.; Mylvaganam, H.; Leiva, R.A.; Berdal, J.E.; Ranheim, T.E.; Johnsen, B.O.; et al. The impact of age on risk assessment, therapeutic practice and outcome in candidemia. Infect. Dis. 2019, 51, 425-434. [CrossRef] [PubMed]

36. Mesini, A.; Mikulska, M.; Giacobbe, D.R.; Del Puente, F.; Gandolfo, N.; Codda, G.; Orsi, A.; Tassinari, F.; Beltramini, S.; Marchese, A.; et al. Changing epidemiology of candidaemia: Increase in fluconazole-resistant Candida parapsilosis. Mycoses 2020, 63, 361-368. [CrossRef] [PubMed] 
37. Brescini, L.; Mazzanti, S.; Orsetti, E.; Morroni, G.; Masucci, A.; Pocognoli, A.; Barchiesi, F. Species distribution and antifungal susceptibilities of bloodstream Candida isolates: A nine-years single center survey. J. Chemother. 2020, 32, 244-250. [CrossRef]

38. Barchiesi, F.; Orsetti, E.; Gesuita, R.; Skrami, E.; Manso, E. Epidemiology, clinical characteristics, and outcome of candidemia in a tertiary referral center in Italy from 2010 to 2014. Infection 2016, 44, 205-213. [CrossRef]

39. Goemaere, B.; Becker, P.; Van Wijngaerden, E.; Maertens, J.; Spriet, I.; Hendrickx, M.; Lagrou, K. Increasing candidaemia incidence from 2004 to 2015 with a shift in epidemiology in patients preexposed to antifungals. Mycoses 2018, 61, 127-133. [CrossRef] [PubMed]

40. Raja, N.S. Epidemiology, risk factors, treatment and outcome of Candida bloodstream infections because of Candida albicans and Candida non-albicans in two district general hospitals in the United Kingdom. Int. J. Clin. Pract. 2021, 75, e13655. [CrossRef]

41. Spiers, R.; Smyth, B.; Lamagni, T.; Rooney, P.; Dorgan, E.; Wyatt, T.; Geoghegan, L.; Patterson, L. The epidemiology and management of candidemia in Northern Ireland during 2002-2011, including a 12-month enhanced case review. Med. Mycol. 2019, 57, 23-29. [CrossRef]

42. Kato, H.; Yoshimura, Y.; Suido, Y.; Shimizu, H.; Ide, K.; Sugiyama, Y.; Matsuno, K.; Nakajima, H. Mortality and risk factor analysis for Candida blood stream infection: A multicenter study. J. Infect. Chemother. 2019, 25, 341-345. [CrossRef]

43. Lausch, K.R.; Dungu, K.H.S.; Callesen, M.T.; Schrøder, H.; Rosthøj, S.; Poulsen, A.; Østergaard, L.; Mortensen, K.L.; Storgaard, M.; Schønheyder, H.C.; et al. Pediatric Candidemia Epidemiology and Morbidities: A nationwide cohort. Pediatr. Infect. Dis. J. 2019, 38, 464-469. [CrossRef] [PubMed]

44. Warris, A.; Pana, Z.-D.; Oletto, A.; Lundin, R.; Castagnola, E.; Lehrnbecher, T.; Groll, A.H.; Roilides, E. Etiology and Outcome of Candidemia in Neonates and Children in Europe: An 11-year Multinational Retrospective Study. Pediatr. Infect. Dis. J. 2020, 39, 114-120. [CrossRef] [PubMed] 